\title{
Leandro Morgenfeld* \\ NUESTRA AMÉRICA \\ FRENTE A LA REACTUALIZACIÓN \\ DE LA DOCTRINA MONROE
}

\section{INTRODUCCIÓN}

Tras casi una década de guerras de independencia en Hispanoamérica, y luego de haberse mantenido prescindente, el gobierno de Estados Unidos decidió que había llegado la hora de horadar la vieja hegemonía europea en el continente. El 2 de diciembre de 1823, el presidente James Monroe planteó en el Congreso la doctrina que llevaría su nombre y cuyo lema era America for the Americans. Traducido, en su uso habitual, significaba que América era para los norteamericanos. $\mathrm{O}$ sea que no permitirían avances de potencias extra-continentales en lo que ellos denominan el Hemisferio Occidental. En su famoso mensaje, Monroe declaró que considerarían cualquier intento europeo de extender su sistema político al continente americano como peligroso para la paz y la seguridad de Washington. La doctrina Monroe era una de las manifestaciones del nuevo expansionismo que Estados Unidos desplegaría en América en las décadas siguientes, construyendo un área de influencia propia, bajo su estricto control. Durante casi doscientos años, fue reactualizada y reinterpretada en diversas ocasiones.

"La doctrina Monroe ha terminado", sostuvo el Secretario de Estado de Barack Obama, John Kerry, el 18 de noviembre de 2013, ante embajadores del continente en la sede de la OEA, tras lo cual agregó "la relación que buscamos [...] no es una declaración de Esta- 
dos Unidos de cuándo y cómo intervendrá en los asuntos de estados americanos, es sobre todos los estados viéndonos como iguales, compartiendo responsabilidad y cooperando en asuntos de seguridad" (Armony, 2014). Ese discurso se inscribía en la estrategia que ensayó Obama en la Cumbre de las Américas de Puerto Príncipe, Trinidad y Tobago (2009) -"buscamos una relación entre iguales con los países de la región"- y procuraba también morigerar los efectos negativos que tuvieron las declaraciones de Kerry del 17 de abril de 2013, ante el Comité de Relaciones Exteriores de la Cámara de Representantes, cuando se refirió ofensivamente a la región como el patio trasero estadounidense, y el espionaje masivo de su gobierno contra líderes regionales como Evo Morales y Dilma Rousseff. Frente a una América Latina que avanzaba -aunque con dificultades- en la construcción de una integración alternativa, impulsando nuevas instituciones como la UNASUR y la CELAC, frente a la creciente presencia de diversos actores extra-hemisféricos, Washington intentaba reposicionarse en una región históricamente estratégica para su proyección imperial.

En la campaña electoral de 2016 reapareció con fuerza un discurso xenófobo y racista, encarnado en el magnate Donald Trump, quien escaló en las encuestas denigrando a los inmigrantes hispanos. Cuando lanzó su candidatura, en junio de 2015, eligió poner a los mexicanos como blanco de sus ataques: "Están enviando gente que tiene muchos problemas, nos están enviando sus problemas, traen drogas, son violadores, y algunos supongo que serán buena gente, pero yo hablo con agentes de la frontera y me cuentan lo que hay" (Ximénez De Sandoval, 2015).

La estigmatización de los hispanos y de otros inmigrantes no fue sólo una (exitosa) estrategia de campaña, sino que se tradujo en la concreción de una serie de iniciativas retrógradas: cinco días después de asumir, Trump firmó una orden ejecutiva para avanzar en la construcción del muro con México, reforzó las guardias fronterizas, amenazó con acelerar y endurecer las deportaciones de los más de once millones de indocumentados -ya no sólo ocupándose de aquellos con procesos criminales- instrumentó sanciones contra las ciudades "santuario" y firmó dos decretos para prohibir el ingreso de ciudadanos de algunos países con mayoría musulmana. Esto fue acompañado de una persistente retórica humillante contra los hispanos, de haber dado de baja el sitio web en español de la Casa Blanca y de criticar la supuesta permisividad en materia migratoria de algunos gobiernos europeos, que incluyó desde críticas a la "catastrófica política migratoria" de Angela Merkel hasta cuestionamientos vía Twitter al alcalde de Londres, Sadiq Khan, luego de un atentado terrorista. 
El señalamiento de la inmigración como un peligro y un flagelo que amenaza a la sociedad es un emergente de la ofensiva ideológica neoconservadora estadounidense, en sintonía con lo que viene ocurriendo en Europa. Para el capital es útil disponer de un mercado de trabajo fragmentado, segmentado y competitivo, lo cual dificulta la organización unificada de la fuerza de trabajo. A través de ese discurso, se alienta la competencia entre trabajadores (legales o ilegales, nacionales o extranjeros) para dificultar la solidaridad y la consolidación de una conciencia de clase. El objetivo es desplazar las tensiones y contradicciones verticales, entre clases sociales, hacia conflictos horizontales, ya sea étnicos, raciales o nacionales. Abordar el tema migratorio, en Estados Unidos, exige analizar las contradicciones fundamentales de un sistema cuyo objetivo es el lucro, y no el bienestar y el enriquecimiento colectivos, a través del intercambio y la convivencia de una sociedad diversa.

Además de profundizar y acelerar la política de deportaciones masivas que ya implementaron Bush y Obama -cinco millones de indocumentados expulsados en los últimos dieciséis años- Trump pretende terminar con un programa clave de su antecesor, DACA (Acción Diferida para los Llegados en la Infancia), que otorga permisos temporales a quienes ingresaron a Estados Unidos siendo niños o niñas.

Más allá de su desdén hacia los hispanos y las agresivas declaraciones contra Cuba y Venezuela, en sus primeros doce meses en la Casa Blanca, Donald Trump no había precisado su política hacia América Latina y el Caribe. Con su discurso en Texas, el 1 de febrero de 2018, antes de su primera gira por la región, el Secretario de Estados Rex Tillerson propuso una reafirmación de la Doctrina Monroe. En forma cínica, se refirió a las actitudes imperiales de China y Rusia, retomó la anacrónica retórica paternalista -que supone que Estados Unidos debe ensañarnos a construir sistemas políticos democráticos- y procuró comprometer a los gobiernos derechistas en su ataque contra los países bolivarianos: "América Latina no necesita nuevas potencias imperiales que solo pretenden beneficiar a sí mismos [sic]. El modelo de desarrollo con dirección estatal de China es un resabio del pasado. No tiene que ser el futuro de este hemisferio. La presencia cada vez mayor de Rusia en la región también es alarmante, pues sigue vendiendo armas y equipos militares a regímenes hostiles que no comparten ni respetan valores democráticos" ${ }^{1}$. Tras su extenso discurso, en una sesión de preguntas con académicos de esa universidad, reivindicó la doctrina que Kerry había dado por muerta hace 5 años:

1 La transcripción del discurso completo puede consultarse en: < https://bit. ly/2MFixyS>. 
"En ocasiones nos hemos olvidado de la doctrina Monroe y de lo que significó para el Hemisferio. Es tan relevante hoy como lo fue entonces" (El Universal, 2018, 1 de febrero).

El anacrónico discurso de Tillerson, con un claro sesgo injerencista, puede tener acogida en los gobiernos derechistas, que tienen afinidad ideológica con ese pronunciamiento más propio de la Guerra Fría y que permanentemente esgrimen el modelo político y económico estadounidense como el que hay que imitar, pero no entre los pueblos, que rechazan la prédica y prácticas xenófobas y anti-hispanas del nuevo presidente estadounidense. Reafirma una tradición secular, pero a la vez le imprime un tono y un estilo que genera urticantes polémicas. Por ejemplo, cuando en una reunión con legisladores en la que discutía la reforma migratoria, el 12 de enero, Trump se refirió a El Salvador y Haití, además de otros países africanos, como "países de mierda", se produjo una crisis diplomática y quejas de múltiples políticos dentro y fuera de Estados Unidos.

En los meses siguientes, Trump iba a concretar su primer viaje a la región, pero volvió a imponerse lo imprevisto. Debía asistir a la Cumbre de las Américas (Lima, 13 y 14 de abril), pero sólo tres días antes del inicio de la misma, canceló su participación. Al mismo tiempo que en la capital peruana se realizaba la gala de recepción de los mandatarios participantes, Trump convocó una conferencia de prensa en la que anunció que estaba bombardeando en ese momento Damasco, la capital siria. Su primer viaje a Nuestra América será para participar en la Cumbre Presidencial del G20 (Buenos Aires, 30 de noviembre y 1 de diciembre de 2018). Más allá del alineamiento del gobierno anfitrión, encabezado por Mauricio Macri, seguramente enfrentará en la capital argentina masivas protestas populares y confirmará por qué genera tanto rechazo en la región.

El objetivo de este artículo será, en primer lugar, analizar las iniciativas de Trump hacia América Latina y el Caribe. En segundo lugar, desarrollar cuáles son las oportunidades, amenazas y desafíos que supone para la región la nueva Administración republicana. Se abordarán las relaciones con Estados Unidos a partir de los distintos caminos y alternativas que se le ofrecen a Nuestra América en esta particular coyuntura, en la que el Departamento de Estado propone una nueva reactualización de la Doctrina Monroe.

\section{MÉXICO, VENEZUELA Y CUBA: TRES PAÍSES EN LA MIRA DE TRUMP}

Para analizar la política de Trump hacia América Latina y el Caribe tenemos que observar, especialmente, tres países que son blanco de sus ataques: México, Venezuela y Cuba. Trump utiliza a los hispanos 
como chivo expiatorio y los humilla para acumular políticamente en el frente interno. México es el gran perjudicado, desde el punto de vista económico, político e ideológico. La nueva Administración también intenta revertir la distensión con Cuba iniciada hace casi tres años por Obama y ataca abiertamente al gobierno venezolano.

México, como consecuencia de haber firmado el Tratado de Libre Comercio de América del norte (TLCAN [NAFTA, por sus siglas en inglés]) hace casi un cuarto de siglo, es económicamente más dependiente que nunca de Estados Unidos. Se ve afectado por razones comerciales, por la presión de Trump para repatriar inversiones estadounidenses en las maquilas mexicanas, por el endurecimiento de los controles fronterizos y por las amenazas de cobrar impuestos a las remesas que millones de mexicanos envían periódicamente a sus familias. Además, de acelerarse las deportaciones, esta afluencia poblacional generaría una presión extra para el mercado laboral, aumentando potencialmente la tasa de desocupación. Producto de esas agresiones, y en medio de una profunda crisis interna, México se debate sobre su futuro ${ }^{2}$.

Cuando hace más de una década argumentábamos por qué había que rechazar el ALCA, poníamos como ejemplo lo perjudicial que estaba siendo el TLCAN para la economía mexicana. A partir de la firma de ese acuerdo, México disminuyó las tarifas arancelarias con Estados Unidos y Canadá (también lo hizo con otros países con los que estableció acuerdos comerciales), en detrimento del resto de los países, que debían enfrentarse a las tarifas de la nación más favorecida.

En términos generales, puede concluirse que, si bien la apertura comercial, la privatización y la desregulación en México favorecieron a parte de su sector exportador, se produjo la desaparición de muchas cadenas productivas, se entregó el sistema bancario y financiero a los inversores extranjeros (pasaron a controlar el $90 \%$ del mismo), en las maquiladoras aumentó significativamente el componente importado, se produjo el colapso del campo frente a la "invasión" de productos agrícolas estadounidenses y se incrementó fuertemente el trabajo informal y "flexibilizado", la miseria y la pobreza, entre otros motivos, por la quiebra de casi 30.000 pequeñas $\mathrm{y}$

2 Recientemente, José Gandarilla, Cecilia Nahón y Leandro Morgenfeld discutieron sobre esta problemática en la sede de CLACSO, en un panel titulado "México, entre Estados Unidos y Nuestra América en la era Trump" (Buenos Aires, 4 de abril de 2017), realizando un diagnóstico muy crítico de las consecuencias económicas y sociales del NAFTA para la población de ese país. Gandarilla expuso allí la crisis del sistema político desatada a partir de la humillante posición de Peña Nieto hacia Trump. 
medianas empresas y la desestructuración de la pequeña producción agrícola. El TLCAN significó, para México, profundizar e institucionalizar las políticas económicas impulsadas por el llamado Consenso de Washington y un obstáculo para acercarlo a Latinoamérica y alejarlo de su poderoso vecino del norte. Hoy el $80 \%$ de las exportaciones se dirigen hacia Estados Unidos -por eso impactó tan negativamente el triunfo de Trump en la economía y en la moneda-, más de cinco millones de campesinos debieron abandonar la actividad agrícola -muchos de ellos son los inmigrantes indocumentados que Trump promete deportar-, México importa maíz de Estados Unidos, aumentó la pobreza a más del 55\%, no hubo una equiparación salarial emtre México y Estados Unidos - pese a las promesas, la brecha se ahondó- y el país vive, además, una catástrofe social, con más de 170.000 muertos, producto de un espiral de violencia descontrolada, asesinatos a periodistas y dirigentes políticos y una militarización de la vida cotidiana sin precedentes ${ }^{3}$.

Ante las amenazas de Trump de salir del TLCAN -producto del fuerte déficit comercial bilateral que le genera a Estados Unidos- o renegociarlo en términos aún más perjudiciales para México, algunos analistas, incluso en México, pretenden maquillar ese acuerdo y mostrar que el país latinoamericano sacó provecho del mismo. Pero no se pueden soslayar las profundas consecuencias regresivas que tuvo ese TLC para las mayorías populares mexicanas.

La llegada de Trump a la Casa Blanca provocó un impacto en México, el país donde el magnate estadounidense tiene peor imagen. Peña Nieto, a través del canciller Luis Videgaray, intentó un acercamiento humillante, que llevó al gobierno mexicano a niveles históricos de impopularidad en 2016. Frente a esta situación, y teniendo en cuenta las elecciones presidenciales del 1 de julio de 2018, parecen abrirse dos caminos alternativos para México. O negocia bilateralmente, en una posición de debilidad, las condiciones de su sometimiento a Trump, o recupera una mirada autónoma, volcada hacia América Latina, e inicia un proceso de redireccionamiento de su inserción internacional y su política exterior, que le permitan ampliar sus márgenes de maniobra.

El discurso agresivo contra Venezuela por parte de Trump apareció ya en la campaña presidencial. Se refirió al gobierno de Nicolás Maduro como una dictadura. Recibió en la Casa Blanca, antes que a ningún otro mandatario latinoamericano, a Lilian Tintori, la esposa del opositor Leopoldo López. Esa retórica injerencista fue acompa-

3 Se estima que hubo más de 200.000 muertes violentas, desde que Felipe Calderón inició la "guerra contra el narco" en 2006. 
ñada de iniciativas concretas. Si ya Obama había tomado medidas extremas contra Venezuela ${ }^{4}$, el nuevo mandatario las profundizó. Incluyó a Tarek el Aissami, vicepresidente de Nicolás Maduro, en la lista de perseguidos por sus supuestos vínculos con el narcotráfico. Este ataque diplomático fue respondido enérgicamente por el gobierno venezolano, quien acusó a Trump de continuar con las maniobras desestabilizadoras e injerencistas de Obama. Poco después, el jefe del Comando Sur, Kurt W. Tidd, compareció ante el Comité de Servicios Militares del Senado estadounidense, señalando que la inestabilidad en Venezuela afectaba a toda la región, repitiendo el latiguillo de que a través de ese país ejercían su influencia Rusia, Irán y China en América Latina. Sectores poderosos en Washington instan a la Casa Blanca y al Congreso estadounidense a realizar un lobby en la OEA para sancionar a Venezuela aplicándole la Carta Democrática Interamericana.

Ante esta situación, que rememora la sufrida por Cuba en la Conferencia de Cancilleres Americanos de Punta del Este de enero de 1962, el gobierno del país caribeño optó por anunciar su salida de esa organización, caracterizada por el Che Guevara como un "ministerio de colonias" de Estados Unidos ${ }^{5}$. Se intenta generar una situación económica y social explosiva, para justificar una suerte de intervención regional humanitaria ${ }^{6}$. En los meses siguientes, aun cuando no lograron frenar las elecciones regionales, continuó la campaña. La primera gira de Rex Tillerson por la región tuvo como objetivo central presionar a los gobiernos aliados -en particular al Grupo de Lima- para aislar a Venezuela, a cuyo gobierno se le retiró la invitación a participar en la VIII Cumbre de las Américas, con el aval o el pedido de Washington.

El caso de Cuba quizás es el más ilustrativo y elocuente de la política de Trump hacia la región. El viernes 16 de junio, desde Miami y en un acto que pareció más propio de la época de la Guerra Fría, el presidente estadounidense puso un freno en el proceso de deshielo

4 Firmó una orden ejecutiva, el 9 de marzo de 2015, en la cual declaró a Venezuela como una "amenaza inusual y extraordinaria a la seguridad nacional" estadounidense. Esta iniciativa fue repudiada por diversos gobiernos latinoamericanos en la VII Cumbre de las Américas, que se reunió en Panamá en abril de ese año. De todas formas, Obama volvió a prorrogar esa disposición al año siguiente.

5 Por razones de espacio, dejamos de lado el análisis del papel poco decoroso desempeñado por Luis Almagro, Secretario General de la OEA. Véase Suárez Salazar (2017b).

6 Sobre las agresiones de Trump contra Venezuela, véase el debate registrado en el Taller "Trump y América Latina", organizado por el EDI y la Fundación Rosa Luxemburgo en Buenos Aires, el 1 de abril de 2017 (Katz, et al, 2017). 
con Cuba iniciado en 2014 por Obama. Rodeado de lo más rancio del anticastrismo, desplegó un agresivo discurso paternalista e injerencista. ¿Qué alcances y límites tiene el (nuevo) giro en la relación con la isla? ¿Cuáles son las causas del abandono de este "legado" de Obama? ¿Cuál fue la respuesta cubana? ¿Cómo va a impactar hacia adentro de Estados Unidos y en las ya de por sí complejas y tirantes relaciones con América Latina y el Caribe?

En primer lugar, vale la pena analizar el qué y el cómo del anuncio de la nueva política de Trump hacia Cuba. El acto realizado en Miami atrasó al menos un cuarto de siglo. El nuevo presidente estadounidense apeló a una retórica agresiva y más propia de la Guerra Fría. Rodeado de lo más retrógrado del exilio cubano, anunció el fin del acuerdo Obama-Castro y firmó el Memorando Presidencial de Seguridad Nacional sobre el Fortalecimiento de la Política de los Estados Unidos hacia Cuba (Trump, 2017), con las nuevas directivas hacia la isla. En síntesis, los cambios que establece son los siguientes:

1. Restringe los viajes turísticos, complicando la obtención de permisos (en los primeros cinco meses del año, 250.000 estadounidenses viajaron a Cuba, lo mismo que en todo el 2016); reafirma el bloqueo económico, comercial y financiero que hace más de medio siglo intenta asfixiar a la isla;

2. Limita los viajes educativos con fines no académicos, que tendrán que ser grupales (prohíbe los viajes individuales auto-dirigidos) y limita las actividades económicas con empresas vinculadas a las Fuerzas Armadas Revolucionarias (básicamente, con el Grupo de Administración de Empresas -GAESA-). Sin embargo, no rompe las relaciones diplomáticas, ni cierra la embajada en La Habana -reabierta hace dos años- ni coloca de nuevo a Cuba en la lista de países que patrocinan el terrorismo, ni limita el envío de remesas, ni prohíbe los vínculos económicos con el sector cuentapropista de la isla, ni modifica los acuerdos migratorios, ni reinstala la política de "pies secos, pies mojados" -derogada por Obama el pasado 12 de enero- que admitía a los cubanos que pisaran suelo estadounidense.

Más allá de que algunas de las medidas generarán complicaciones económicas en Cuba, lo más grave es el tono. El acto, de fuerte contenido simbólico, se realizó en la Pequeña Habana, en el Teatro Manuel Artime, justamente denominado así en homemaje al contrarrevolucionario que fuera el jefe civil de la Brigada 2056, aquella que invadiera la isla en Playa Girón, en abril de 1961 ("Es un honor estar en un teatro que lleva el nombre de un verdadero héroe del pueblo cubano [...] Estamos muy honrados de que nos acompañen los asombrosos veteranos de la Bahía de Cochinos", dijo Trump). 
El presidente estadounidense habló luego del vice Mike Pence, el gobernador de La Florida Rick Scott, el senador de origen cubano y ex precandidato republicano Marco Rubio y el representante Mario Díaz-Balart (un día antes, este diputado había declarado: "Trump no está con los que reprimen al pueblo cubano como estaba Obama"). Calificó al sistema político isleño como una "dictadura" y desplegó un discurso agresivo, que se emparenta con su irrespetuoso mensaje de noviembre de 2016, cuando falleció Fidel Castro. Se refirió al gobierno de La Habana como el "brutal régimen castrista" y destacó que "haremos cumplir el embargo". El acto fue la puesta en escena del retorno a la política agresiva que desplegaron sin éxito Eisenhower, Kennedy, Johnson, Nixon, Ford, Carter, Reagan, Bush, Clinton, Bush Jr. y Obama, al menos en su primer mandato.

¿Por qué la vuelta a una retórica más propia de la Guerra Fría? ¿Por qué reivindicar el fracasado bloqueo, repudiado cada año en forma casi unánime en la ONU -en la última Asamblea General, ciento noventa y un países exigieron su levantamiento, y sólo Estados Unidos e Israel se abstuvieron-? ¿Por qué insistir con una política que genera rechazo no sólo en la población estadounidense en general -según un sondeo de The New York Times de 2016, el $62 \%$ de la población estaba de acuerdo con el nuevo enfoque de Obama hacia Cuba- sino de los propios cubanoamericanos -el $70 \%$ de los cubanoamericanos de Miami apoyaban la normalización, mientras que el respaldo al bloqueo había caído a un 37\%, en comparación con el 84\% de 1990-? La principal causa del giro tiene que ver con la política interna de Estados Unidos. En primer lugar, es una "devolución de favores". Trump modificó su anterior posición favorable al deshielo para obtener el apoyo del establishment cubanoamericano, que le permitió ganar en la Florida, por un margen muy estrecho.

Pero la escenificación del trato duro con Cuba también responde a sus necesidades políticas, en dos sentidos. Trump fue el presidente menos popular en sus primeros cien días, al menos desde que esto se mide en los años sesenta. Cosecha altísimos niveles de rechazo, enfrenta movilizaciones de mujeres, trabajadores, estudiantes, científicos, ecologistas, inmigrantes y pueblos originarios. Sufrió importantes reveses políticos (para imponer su veto migratorio, para aprobar el TrumpCare, para financiar el muro con México) y enfrenta el llamado RusiaGate, que involucra a importantes funcionarios de su entorno y amenaza con obstaculizar o interrumpir su presidencia a través de un impeachment. Sin embargo, conserva el apoyo de sus votantes, aunque estos representaron apenas el $27 \%$ del padrón. Ese es el sentido de este tipo de puestas en escena: reforzar su base política, atacando 
todo lo que sea considerado parte del "legado" de Obama (y, el deshielo con Cuba, sin dudas, era un componente central del mismo). Exhibe una supuesta fortaleza hacia adentro, abroquela a sus seguidores ultraconservadores, y a la vez proyecta una imagen hacia afuera que refuerza su disposición a actuar de manera unilateral, sin tener en cuenta lo que opine la comunidad internacional: no le importa lo que diga la ONU sobre el bloqueo.

Claro que, cuando hablamos de cómo la política interna condiciona su política exterior, también nos referimos a cuestiones menos transparentes: Trump necesita el apoyo de su ex rival interno Marco Rubio, quien integra la Comisión de Inteligencia del Senado, que es la que investiga si Rusia intervino en las elecciones del año pasado en connivencia con el magante. Una semana antes de los anuncios sobre Cuba, ante esa comisión compareció James Comey, el ex jefe del FBI, expulsado por Trump pocos días antes. Rubio intercedió en el Senado para que Comey aclarara que Trump "no se encontraba personalmente bajo investigación". La posición de este senador será clave para determinar el futuro de la investigación sobre la trama rusa. Como se ve, no sólo en América Latina hay una estrecha relación entre política exterior y política interior, a pesar de lo que plantean los acríticos defensores de la "gran democracia" del Norte. En síntesis, el acto en Miami tuvo el triple objetivo alejar la atención mediática del affaire Rusia, que había alcanzado su clímax por esos días, consolidar la base de apoyo republicana y devolver el favor electoral de los cubanoamericanos de Florida.

Esta agresividad registró un nuevo capítulo hacia el segundo semestre de 2017. Tras denunciar un supuesto "ataque sónico" contra diplomáticos estadounidenses apostados en La Habana ${ }^{7}$, el 29 de septiembre la Administración Republicana resolvió reducir al mínimo la misión diplomática en la isla. Hizo volver a veintiún diplomáticos, congeló el otorgamiento de visas a cubanos y recomendó que sus ciudadanos no viajaran a Cuba. El 3 de octubre, además, resolvió expulsar a quince diplomáticos cubanos que cumplían funciones en la embajada en Washington. El secretario de Estado, Rex Tillerson, quien aclaró que de todas formas no se rompían las relaciones diplomáticas, explicó: "La decisión se tomó por la incapacidad de Cuba de dar los pasos apropiados para proteger a nuestros diplomáticos de acuerdo con sus obligaciones bajo la Convención de Viena" (Página/12, 2017, 4 de octubre).

Cedió así, una vez más, ante el poderoso senador Marco Rubio, quien aplaudió esta medida: "La embajada de los Estados Unidos en

7 Si bien no se acusó al gobierno cubano, el Departamento de Estado lo responsabiliza por no cuidar los diplomáticos estadounidenses. 
La Habana debería ser reducida a una sección de intereses y debemos estar preparados para considerar medidas adicionales contra el régimen de Castro si estos ataques continúan" (Página/12, 2017, 4 de octubre).

La respuesta del gobierno cubano no se hizo esperar. En conferencia de prensa, ese mismo día en La Habana, el canciller Bruno Rodríguez declaró: "El gobierno de Estados Unidos, con estas acciones políticamente motivadas e irreflexivas, es el responsable del deterioro presente y probablemente futuro de las relaciones bilaterales"(Página/12, 2017, 4 de octubre). Este nuevo incidente, instigado por el lobby cubanoamericano de Florida, es una muestra más de la hostilidad de la Casa Blanca hacia toda Nuestra América, y seguirá socavando la ya alicaída imagen de Trump en la región.

\section{LOS ALIADOS DE TRUMP EN PROBLEMAS}

Para atacar a los países no alineados, Trump busca subordinar a los gobiernos neoliberales que quedaron descolocados por su prédica proteccionista. Si Peña Nieto y Temer no pueden cumplir hoy cabalmente el rol de alfiles de Washington -ambos tienen bajísimos niveles de aprobación interna- los candidatos son Santos ${ }^{8}$, Kuczynski -hasta que debió renunciar en marzo de este año por los escándalos de corrupción- y Macri. El peruano fue el primer mandatario latinoamericano en ser recibido en la Casa Blanca, en febrero, y Macri negoció y logró una escueta llamada telefónica de Trump unos días antes. Allí el argentino se mostró dispuesto a seguir al pie de la letra la agenda de Washington. No planteó ni solidaridad con México ni reclamó por la negativa al ingreso de limones al mercado estadounidense -uno de los productos agrícolas argentinos que deben enfrentar las medidas fitosanitarias con las cuales Estados Unidos despliega su proteccionismo selectivo-. La única preocupación del mandatario argentino era lograr que Trump lo recibiera en Washington, cuestión que ocurrió, como veremos más abajo, el 27 de abril. Como planteó la entonces canciller argentina, Susana Malcorra, pretendían aprovechar las dificultades de sus pares de México y

8 Más allá de los vínculos entre los presidentes, Estados Unidos apuesta a fortalecer la alianza estratégica con Colombia. En su visita a la Casa Blanca, realizada el 17 de mayo, Santos ratificó la vocación de su gobierno de continuar la subordinación militar y las agresiones contra Venezuela. Sin embargo, Trump también mantuvo conversaciones con opositores al actual gobierno colombiano y a los acuerdos de paz con las FARC, como los ex presidentes Álvaro Uribe y Andrés Pastrana. Sobre los acuerdos alcanzados y la continuidad en el financiamiento del "Plan Colombia", véase Suárez Salazar (2017b). 
Brasil para que Macri se transformase en el interlocutor privilegiado de Trump.

Los gobiernos neoliberales que apostaban a la continuidad con Clinton y a la firma y extensión de acuerdos como el TLCAN y el Acuerdo Transpacífico de Cooperación Económica (TPP, por sus siglas en inglés), ahora están obligados a recalcular su inserción internacional. Se les dificultará seguir con la política de promoción del libre comercio, endeudamiento externo masivo y concesiones para atraer inversiones estadounidenses. El contexto mundial está siendo mucho más adverso (Crespo, 2017: 11-14). Cantan loas a la globalización neoliberal, cuando en Estados Unidos y Europa está siendo impugnada. En Argentina, por ejemplo, representantes del gobierno ya hablan de la necesidad de diversificar mercados y desplegar una política exterior menos enfocada en Washington y la Unión Europea, justo lo contrario a lo que hicieron desde que llegaron al poder.

El caso del nuevo gobierno argentino, el primero que "recuperó" la derecha regional, es sintomático9. La política externa desplegada por Macri profundiza la inserción dependiente. Apenas es beneficiosa para una minoría concentrada: los bancos, los socios menores del gran capital trasnacional y los grandes exportadores, beneficiados por la baja de retenciones y por la mega-devaluación de diciembre de 2015. Sin embargo, hubo un análisis erróneo del contexto internacional. Se promovió una apertura comercial irrestricta en función de avanzar con tratados de libre comercio, justo cuando las potencias occidentales avanzan en sentido contrario. Se pagó lo que exigían los fondos buitre, elevando enormemente el endeudamiento externo. Sigue cayendo la actividad (el PIB retrocedió $2,3 \%$ en 2016, según el INDEC), aumentan la pobreza y la desigualdad, la inflación no cede y la deuda externa se dispara, incluyendo el reciente bono a cien años ${ }^{10}$.

Más allá de estas advertencias, el gobierno argentino buscó desesperadamente el contacto con Trump. Luego de intensas gestiones, el 27 de abril de 2017, Macri finalmente logró la foto en la Casa Blanca. ¿Por qué el magnate no le recriminó públicamente su explícito apoyo a Hillary Clinton en las elecciones en 2016? Simplemente porque encuentra en el presidente argentino el delegado que necesita para reconstituir el poder de Estados Unidos en América Latina, una región que en los últimos años supo coordinar políticas no siempre

9 Analizamos en detalle la relación Macri-Trump y su impacto regional en Morgenfeld (2017b).

10 Este bono fue calificado como "la locura más grande del mundo", según un editor del Finantial Times (Clarín, 2017,27 de junio). 
subordinadas a Washington. Más allá de la retórica ofensiva que desplegó en la campaña, el republicano precisa consolidar el dominio que históricamente su país ejerció en la región. Ante la debilidad política de los mandatarios de Brasil y México, Macri es el ideal: casi sin pedir nada a cambio, viene tomando acrítica y pasivamente los puntos de la agenda política, económica, militar e ideológica de Estados Unidos.

La frase que resume el encuentro es aquella que pronunció Trump ante los periodistas, antes de reunirse en el Salón Oval: "Él me va a hablar de limones, yo de Corea del Norte". Humillante, sí, pero certera. Y Macri no contestó nada. Es más, apenas pudo pronunciar una palabra ante los periodistas, ante la verborragia del magnate. Pocos días después, se confirmaron las magras concesiones: los limones argentinos por fin podrían entrar al mercado estadounidense (tema negociado hace años y ya anunciado por Obama en diciembre) y habría cierta facilidad en el trámite migratorio para argentinos que viajen a hacer negocios a Estados Unidos. La contracara es la amenaza a las exportaciones de biodiesel argentino al país del norte. Los limones sumarían apenas cincuenta millones de dólares. Las restricciones al biodiesel, en cambio, podrían generar pérdidas por unos 1.300 millones $^{11}$.

Pero eso no es lo más grave. Macri promete concesiones a los inversores, que van desde una menor regulación medioambiental, en el caso de la minería, a rebajas impositivas y del "costo laboral" (flexibilización mediante). O sea, peores condiciones para la mayoría de la población, además de una mayor extranjerización de la economía y una profundización del esquema extractivista. Desde el punto de vista político, Macri apuesta a la OEA, en detrimento de la UNASUR y la CELAC, y ataca a los países no subordinados a Estados Unidos, como Venezuela, hoy el principal blanco de ataque de las derechas regionales y el Departamento de Estado ${ }^{12}$. Además, se incrementan la compra de armas y la injerencia de las fuerzas armadas estadounidenses.

¿Qué más puede pedir Trump? Todo a cambio de una foto en la Casa Blanca, unas palmadas en la espalda, elogios y algunos

11 Para una historia del proteccionismo selectivo de Estados Unidos y cómo afectó el ingreso de bienes agropecuarios argentinos en ese mercado, véase Rapoport y Morgenfeld (2017).

12 En ocasión de la visita de Obama, ambos gobiernos firmaron, el 23 de marzo de 2016, una declaración conjunta para hacer a la OEA "más relevante, eficiente, efectiva, financieramente sólida, y enfocada en lograr resultados que ayuden a asegurar una región más democrática, segura y próspera para todos sus habitantes". 
limones. El problema es que ya se experimentó, en la Argentina, en la década de 1990, lo negativas que resultaron las "relaciones carnales" 13 con Estados Unidos. Esta orientación se profundizó durante la gira sudamericana del vice-presidente Mike Pence, quien visitó Colombia, Chile, Argentina y Panamá, entre el 13 y el 17 de agosto de 2017.

El 14 de agosto se produjo la llegada del vicepresidente de Estados Unidos, Mike Pence. El mandatario estadounidense llegó días después de la temeraria amenaza de Trump de una intervención militar en Venezuela. Tras el encuentro con Macri, en el que elogió la política económica que viene implementando, anunciaron un acuerdo para habilitar el todavía demorado ingreso de limones en Estados Unidos, pero a la vez para permitir la exportación de carne porcina hacia la Argentina, lo cual produjo quejas de los productores locales, quienes denunciaron el riesgo de perder hasta 35.000 puestos de trabajo.

Apenas una semana más tarde, el 22 de agosto, se conoció la decisión del Departamento de Comercio de Estados Unidos de cobrar aranceles prohibitivos (57\% en promedio) a las importaciones de biodiesel provenientes de Argentina, ratificada en los primeros días de 2018. Esas ventas significaron en 2016 el 25\% de las exportaciones al país del norte. Esta decisión produjo un cimbronazo en el gobierno argentino, quejas de múltiples productores y corporaciones agropecuarias y la muestra cabal del fracaso de la política de alineamiento, que hasta ahora no produjo ventajas económicas en el vínculo bilateral.

Esta decisión del Departamento de Comercio de aplicar elevados aranceles al biodiesel argentino, anunciada apenas una semana después de la visita del vicepresidente estadounidense, echa por tierra las expectativas de una mayor convergencia comercial bilateral. El gobierno argentino insiste en abrir la economía, pero no logra revertir el proteccionismo agrícola de Estados Unidos y Europa, con lo cual la balanza comercial arroja saldos negativos. El déficit comercial del 2017 fue récord (8154 millones de dólares). El 22 de diciembre se anunció el reingreso de la Argentina al Sistema Generalizado de Preferencias - programa de rebaja limitada de aranceles a países "en desarrollo"-, del que había sido suspendido nuestro país en 2012 por los conflictos con empresas estadounidenses ante el CIADI", pero hay presiones para que Trump elimine directamente esos beneficios. La buena noticia fue opacada por la

13 Así las calificó el propio Guido Di Tella, canciller de Menem y promotor de una política alineada con Washington. 
confirmación, el 4 de enero de 2018, de un arancel del 72\% al biodiesel argentino por parte del Departamento de Comercio estadounidense, bloqueando exportaciones que proyectaban llegar a 1.500 millones de dólares este año. En marzo, además, se anunciaron nuevas medidas proteccionistas contra el acero y aluminio -se fijó una cuota máxima para la Argentina- lo que profundizaría aún más al déficit comercial bilateral en 2018. A su vez, el incremento de tasas por parte de la Reserva Federal provocó una mega-devaluación del peso argentino en abril y mayo y el anuncio del gobierno de la vuelta a endeudarse con el Fondo Monetario Internacional, luego de doce años.

\section{UNILATERALISMO Y MILITARIZACIÓN DE LA POLÍTICA EXTERIOR HACIA NUESTRA AMÉRICA}

El unilateralismo, injerencismo y militarismo de Trump son una amenaza creciente para Nuestra América. Ya repasamos los ataques contra México, Venezuela y Cuba. Pero no son los únicos. Un día antes del retrógrado acto en Miami, el 15 de junio, Mike Pence había disertado sobre las supuestas amenazas a la seguridad nacional de Estados Unidos provenientes de países centroamericanos como El Salvador, Honduras y Guatemala, a causa del narcotráfico y las pandillas. Pidió la colaboración de Sudamérica con Estados Unidos, en la lucha contra este flagelo. Este tipo de iniciativas son un avance más en la fracasada estrategia de la guerra contra las drogas, al igual que la lucha contra el terrorismo, como excusas para aumentar el injerencismo militar -más bases, operaciones conjuntas, espionaje militar, venta de armamento-. El 3 de mayo, el todavía Secretario de Estado Rex Tillerson había anunciado a funcionarios de la cancillería de su país cuál sería la política hacia la región:

1. "Lo que queremos hacer es lograr una nueva perspectiva (step back) y desarrollar una estrategia para el Hemisferio Occidental que piense América del Sur como un todo y sus relaciones con América Central, al igual que con Cuba y el Caribe. [...] Hay asuntos vinculados al financiamiento del terrorismo. Hay redes terroristas que han comenzado a emerger en partes de América del Sur que requieren nuestra atención. Hay asuntos de gobernabilidad en ciertos países seguramente ustedes están siguiendo la situación en Venezuela; una real tragedia, pero estamos esperanzados que trabajando con otros [...] estaremos en posibilidades de ganar cierta influencia en Venezuela (Suárez Salazar, 2017b).

2. Con Trump asistimos a una militarización de su política exterior y esto es particularmente preocupante en Nuestra América, que a pesar de ser una zona de paz, sufre esta avanzada de la diplo- 
macia militar -más recursos para el hard power, en detrimento del soft power- ${ }^{14}$.

3. También aspira a recuperar el control del Canal de Panamá, fundamentalmente ante la "amenaza" que supone la construcción de otro canal bioceánico en Nicaragua, financiado con capitales chinos (Gandásegui, 2017: 7).

4. En el acto encabezado por Trump en Miami no sólo se atacó a Cuba, sino también a Venezuela. El día anterior, Pence había declarado en ese mismo sentido: "Todos nosotros debemos elevar nuestras voces para condenar al gobierno venezolano por su abuso de poder y su abuso contra el propio pueblo, y hacerlo ya" (Página/12 2017, 18 de junio). Ese mismo día el secretario de Estado, Rex Tillerson, había alertado, sin datos, sobre supuestas conexiones entre los carteles mexicanos de la droga y los fundamentalistas del Estado Islámico. John Kelly, el secretario de Seguridad Nacional -antes jefe del Comando Sur- también insistió en el supuesto vínculo entre "redes terroristas y redes criminales" como los narcos. O sea, vale utilizar cualquier argumento -terrorismo, narcotráfico, pandillas- para justificar la militarización de la política de Estados Unidos hacia nuestra América (Granovsky, 2017).

Si Trump elige volver a ese tipo de iniciativas, crecerá aún más el rechazo que su figura provoca en la región por el muro en la frontera con México, su estigmatización de los hispanos y su política exterior unilateralista y militarista. Como señaló el presidente boliviano Evo Morales, en la apertura de la Conferencia Mundial de los Pueblos, realizada en Tiquipaya, Bolivia, ante representantes de 43 países: "Son los mismos que cierran las puertas y construyen muros para impedir que las personas que huyen de esas guerras militares o económicas salven sus existencias [...] Los muros entre pueblos son un atentado a la humanidad; no protegen, enfrentan; no unen, dividen [...] van en contra de la historia de la humanidad; mutilan la ciencia y el conocimiento; encienden el odio a la diferencia; ahogan la libertad" (Cambio 2017, 20 de junio).

\section{REFLEXIONES FINALES. LOS DOS CAMINOS FRENTE A TRUMP: SUBORDINARSE O ENFRENTARLO}

Trump está concitando un amplísimo rechazo internacional, como ocurrió con Bush jr., o peor. En junio de 2017 se conoció la noticia del aplazamiento de la visita de Trump a Londres, para evitar las múltiples protestas callejeras que se estaban organizando.

14 Hay, en ese sentido, una reversión parcial de la estrategia de dominación estadounidense que primó con Obama. 
El rechazo que suscita Trump es particularmente alto en Nuestra América. Se destaca México, pero también alcanza a la Argentina, a pesar del alineamiento del presidente Macri. Esto, puede implicar un problema para Estados Unidos: cuando se dirija a la Cumbre presidencial del G20, le será complicado evitar movilizaciones de protesta. Y esto genera también una dificultad para sus aliados, como el presidente Macri. No es lo mismo aparecer sonriente frente al carismático Obama, que frente al revulsivo Trump. El "fantasma" de Mar del Plata (2005) -pero también el recuerdo de las protestas que debieron enfrentar Nixon (1958) y Rockefeller (1969)- recorrerá la región cuando Trump nos visite en 2018.

La reunión de Buenos Aires será, si cumple su compromiso de asistir, el primer viaje de Trump a América Latina. Tenía proyectado asistir a la VIII Cumbre de las Américas, en Lima, el 13 y 14 de abril, pero por la decisión de bombardear Siria, tras el supuesto uso de armas químicas en Duma, el 7 de abril, terminó cancelando a último momento su participación, en la que fue la más deslucida reunión de mandatarios americanos desde que ser realizó el primero de estos cónclaves hace 24 años. Según una encuesta de Pew Research Center, dada conocer en las vísperas de la reunión en Lima, el $82 \%$ de los latinoamericanos consideran a Trump arrogante, el 77\% intolerante y el $66 \%$ peligroso. La opinión favorable sobre Estados Unidos cayó 19\% desde la Cumbre de las Américas de 2015, la última a la que asistió Obama.

Nuestra América atraviesa una hora incierta, en el que se avizoran dos caminos. O se imponen los gobiernos derechistas, que están dispuestos a asumir un rol subordinado frente a la Casa Blanca, aún si quien la ocupa temporalmente sostiene un discurso xenófobo, anti-hispano y crítico de los acuerdos de libre comercio, o se construye una alternativa superadora, en oposición a la prepotencia injerencista y militarista que impulsa la máxima autoridad de la principal potencia imperial. El dilema es crucial para las fuerzas de izquierda, populares y progresistas de Nuestra América. Ante la ofensiva imperialista de Trump es crucial y urgente construir una alternativa superadora, que vaya más allá de la mera posición defensiva frente al avance del capital trasnacional más concentrado.

A gobiernos derechistas, como los de Macri, Temer o Peña Nieto -o el ahora reelecto Sebastián Piñera- impulsores de los tratados de libre comercio y de la apertura económica indiscriminada, alinearse con el impopular Trump les hará pagar un costo político interno alto. Nuestra América debe avanzar con una agenda propia, descartar las estrategias aperturistas y subordinadas a Estados Unidos. El fracaso de las socialdemocracias europeas y del Partido Demócrata en Esta- 
dos Unidos, que a pesar de su prédica progresista implementaron un ajuste neoliberal, tiene que ser una lección para las fuerzas populares y de izquierda. $\mathrm{O}$ se avanza con una crítica radical y se construyen alternativas, o la impugnación a la globalización neoliberal será aprovechada por los líderes neofacistas o de extrema derecha ${ }^{15}$.

El fracaso de la estrategia de Macri de dar la espalda a la región para congraciarse con Trump muestra la necesidad de converger con los demás países latinoamericanos para negociar con las potencias extra regionales desde una posición de mayor fortaleza. Vinculándose individualmente con una gran potencia, Argentina -o cualquier país de la región- tiene las mayores chances de perder. En cambio, hay ejemplos históricos de negociaciones exitosas cuando se alentó la convergencia con otros países similares. En la reunión ministerial de la Organización Mundial del Comercio (OMC) realizada en Cancún, en 2013, convergieron los países exportadores de bienes primarios y se pusieron de acuerdo para paralizar las negociaciones en tanto no se discutieran los subsidios agrícolas de Estados Unidos, Europa y Japón. La liberalización del comercio no puede abarcar solamente a la industria y los servicios. Algo similar ocurrió dos años después, cuando los países del Mercosur, más Venezuela, impidieron que avanzara el proyecto del ALCA.

En síntesis, Trump es un gran peligro -sus iniciativas misóginas, xenófobas, anti-obreras, plutocráticas, militaristas, injerencistas y contra cualquier protección del medio ambiente provocan una alarma en el el mundo entero- pero a la vez una oportunidad, por el rechazo que genera, para retomar la integración latinoamericana con una perspectiva antiimperialista y anticapitalista, y al mismo tiempo ampliar la coordinación y cooperación políticas, confluyendo con las organizaciones populares que lo enfrentan en Estados Unidos. Con Trump, a la clase dominante estadounidense, y a sus gobiernos aliados en la región, se les complica desplegar el imperialismo moral. Con el actual ocupante de la Casa Blanca, les cuesta mostrar a Estados Unidos como el líder de los organismos multilaterales, que cuida las democracias, el planeta y los valores occidentales, respetando las normas de la diplomacia internacional. Como declaró Julián Assange, el líder de Wikileaks, si Obama era "un lobo con piel de cordero", Trump es un "lobo con piel de lobo" ${ }^{16}$. Expresa descarnadamente el afán de dominio imperial sobre Nuestra Amé-

15 Los buenos resultados electorales obtenidos en los dos últimos años por Bernie Sanders, Jean-Luc Melenchón y Jeremy Corbyn muestran la necesidad de profundizar un discurso crítico, en vez de optar por variantes centristas.

16 Página/12 2017 (Buenos Aires) 5 de febrero. 
rica. Esta prepotencia fue convalidada por el entonces Secretario de Estado Tillerson, en el discurso en Texas, el 1 de febrero, y en su ulterior gira latinoamericana. Y eso puede incrementar aún más el rechazo a la subordinación claudicante que proponen las derechas regionales como único camino posible. Ante los dos caminos posibles, aceptar el dominio neocolonial, subordinándose a Estados Unidos, o avanzar en la postergada confluencia de Nuestra América, sólo el segundo permitirá una inserción internacional más autónoma, condición necesaria para avanzar en la construcción de un orden social menos desigual y depredatorio.

Buenos Aires, 15 de mayo de 2018.

\section{BIBLIOGRAFÍA}

Armony, Ariel 2014 "La era de la doctrina Monroe ha terminado": El discurso que ignoramos en 2013" en El País (Madrid) 11 de enero

Casselman, Ben 2016 “There Aren't 2 To 3 Million Undocumented Immigrants With Criminal Records For Trump To Deport" en Fivethirtyeight, 14 de noviembre. En < https://53eig.ht/2MpgyyJ $>$.

Crespo, Horacio 2017 "Difícil pasado, futuro incierto. Desde la política del gran garrote al proteccionismo de Trump" en Edición Especial de Le Monde Diplomatique Cono Sur "América Latina territorio en disputa" (Buenos Aires: Capital Intelectual) junio

Katz, Claudio et al 2017 Trump y su impacto en la región. Reflexiones sobre la situación económica mundial y sus perspectivas (Buenos Aires: Fundación Rosa Luxemburgo-EDI)

Morgenfeld, Leandro 2017 "Fracasa la OMC y emergen las alternativas" en Semanario Brecha, Número 1674 (Montevideo)

Morgenfeld, Leandro 2017b "Macri y el fracaso de la subordinación a Estados Unidos: de Obama a Trump" en IADE-Realidad Económica, 18 de enero de 2017

Nahón, Cecilia y Morgenfeld Leandro 2018 "Doce datos para entender a Trump" en Anfibia (Buenos Aires) 19 de enero < https://bit.ly/2JQ340t>

Pozzi, Pablo 2016 "Las elecciones de Estados Unidos. Raza, racismo y el electorado" en Huellas de Estados Unidos N. 11 (Buenos Aires) octubre

Preciado, Jaime y Gandásegui (h), Marco (comps.) 2017 Hegemonía y democracia en disputa. Trump y la geopolítica del neoconservadurismo (México: ALAS-CLACSO)

Rapoport, Mario y Morgenfeld, Leandro 2017 "Proteccionista forever. Argentina y Estados Unidos en la era Trump" en Página/12 
(Buenos Aires), Suplemento Cash, pp. 1-3, 5 de febrero

Suárez Salazar, Luis 2017a "El gobierno temporal de Donald Trump: una redoblada amenaza para Nuestra América" en Revista Con Nuestra América, Costa Rica, 21 de enero

Suárez Salazar, Luis 2017b "Las políticas hacia América Latina y el Caribe del gobierno temporal de Donald Trump: una aproximación a sus primeros 155 días" en Preciado, Jaime y Gandásegui (h), Marco (comps.) Hegemonía y democracia en disputa. Trump y la geopolitica del neoconservadurismo (México: ALAS-CLACSO)

Trump, Donald 2017 "National Security Presidential Memorandum on Strengthening the Policy of the United States Toward Cuba" Washington, 16 de junio

Ximénez De Sandoval, Pablo 2015 "Donald Trump insulta a los mexicanos al anunciar su candidatura" en El País (Madrid) 17 de junio. 